\title{
CAG NEWS PAGE
}

\section{Looking forward: The Canadian Association of Gastroenterology strategic plan}

Ronald J Bridges MD FRCPC, Past President, CAG, University of Calgary, Calgary, Alberta

David Morgan MD FRCPC, President, CAG, McMaster University, Hamilton, Ontario

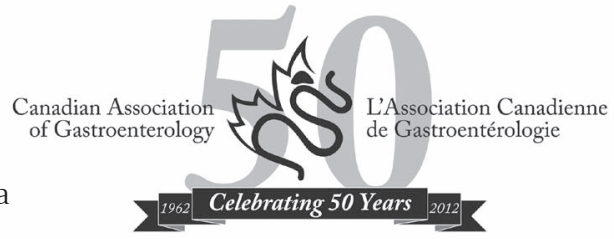

Paul Sinclair MSc, Executive Director, CAG National Office, Oakville, Ontario

Dan Sadowski MD FRCPC, President-Elect, CAG, University of Alberta, Edmonton, Alberta

$E^{s i n}$ stablished in 1962, the Canadian Association of Gastroenterology $(\mathrm{CAG})$ promotes and is committed to advancing the highest standards of scientific study, training and clinical practice related to digestive health and disease. The association is built on broad principles, and brings together clinicians, researchers, educators and related personnel from across disciplinary and geographical boundaries and all stages of professional life. Today, the CAG is comprised of more than 1100 members who are actively involved in research, education and patient care in all areas of digestive health and disease, contributing to the physical, economic and social health of all Canadians. In a leadership role, the CAG has traditionally promoted the advancement of the science, art and practice of gastroenterology by supporting training and education at all levels, and by sustaining and engaging in the advancement of the study of digestive health sciences and diseases. The CAG's accomplishments have energized the gastrointestinal research community, inspired the delivery of educational and training programs, and facilitated the development of clinical guidelines and quality initiatives.

The first strategic plan - The 1993 Canadian Association of Gastroenterology Strategic Plan: Excellence in Achievement - was an important step to further the growth and development of the organization as a national leader for digestive health care research, education and clinical care (1). In 2004, building on the accomplishments of the preceding 42 years of work, the second CAG strategic plan articulated the organization's vision, mandate and strategic directions for the period 2004 to 2010 (2). This plan was structured into five principal initiatives with associated specific goals and targets. As evidenced in a recent review of the accomplishments related to these goals (3), there is much to celebrate and we can rightly take pride in the accomplishments of the organization.

The CAG is now entering a new chapter in its history and, as such, it is appropriate and critical to review and renew the strategic plan. The changes, challenges and opportunities confronted by the organization necessitated thorough self-examination leading to the development of the third strategic plan. With that in mind, in 2009, the CAG Board initiated a planning process culminating in the development of the present strategic plan that outlines the aspirations and focus for the organization for the coming five years. The plan is built on a strong existing foundation and is developed at a pivotal time for the field of gastroenterology; the emergence of new knowledge and technologies are transforming the specialty and require careful consideration in planning priority initiatives. The strategic plan is unveiled during a period of significant uncertainty. We are facing new and formidable challenges in all areas: research funding and competition, training/ education, and clinical care with sicker patients and often with limited resources. We must choose carefully where to invest our time, energy and resources. Regardless of the choices, we must always strive for excellence. The development of the strategic plan reinforces the organization's commitment to serving all of its members and honouring and supporting each core constituency.

\section{STRATEGIC PLANNING PROCESS}

The initial step in formulating the current strategic plan was a February 2009 CAG Board review of the 2004 plan. All of the goals and targets associated with the five principal initiatives in the 2004 strategic plan have been addressed and most have been fully or partially achieved (3). To inform the development of the next five-year strategy, the $\mathrm{CAG}$ wanted to engage and involve a representative cross section of its members from across Canada. The geographically diverse nature of the organization necessitated the use of online surveys and questions to collect information and to allow all members and related stakeholders the opportunity to provide meaningful input to the development of a new plan.

In June 2009, an online strategic planning survey and a process involving a series of three online discussion forums focusing on specific questions were initiated and yielded critical information that informed the discussion at the strategic planning retreat. The strategic planning survey was completed by 187 members of the organization representing diverse regions and areas. One hundred forty-two members engaged in the discussion forum generating significant commentary and extensive documentation. The responses to the questions and survey played an important role in shaping the development of the strategic plan.

The content of the CAG strategic plan emerged during a planning retreat convened in September 2009. A diverse group of CAG members reviewed the commentary, and information gathered from the survey and discussion forums and discussed, deliberated and developed a highquality five-year strategic plan for review by the CAG Board. The strategic planning retreat used an interactive, comprehensive and iterative process to bring these members together to engage in collective thinking. The process is a science-based method that enables large groups of people to leverage their collective intelligence over the course of a few days for the purpose of formulating an executable plan (4). On arrival at the retreat, participants were guided through a process in which they individually and collectively proposed, debated and arrived at consensus on an eight-point agenda, which they deemed to be the most important facets of the discussion about the opening question - "What must the CAG start, continue, and/or stop doing to optimize the value we deliver to our members while enhancing the delivery of digestive healthcare to Canadians?" The key objectives of the session were to identify the specific priorities, goals and initiatives that the members believe should be the focus of CAG activities over the next five years. There was productive dialogue and candid debate among the participants to address major issues leading to development of the CAG strategic plan. The plan was subsequently reviewed and approved by the CAG operational committees and the Board before presentation to the membership at the Annual General Meeting in February 2010.

\section{The CAG is proud to acknowledge its Benefactor Corporate Sponsors:}

\section{Abbott Canada AstraZeneca Canada Inc}

Olympus Canada Inc 


\section{STRATEGIC PLAN GOALS}

The CAG strategic planning process identified six goals, outlined below in no particular order, and an overarching communications principle:

\section{Goal 1}

The CAG and Canadian Digestive Health Foundation (CDHF) will advocate for and facilitate the development of a renewed and larger vision of digestive health, plus champion a National Digestive Health Strategy by engaging all digestive health stakeholders, and encourage their support for this unified vision and strategy, by:

- Raising public awareness of digestive health;

- Generating stable funding for the delivery of clinical care and research;

- Being viewed as a leader in developing Canadian health policy in digestive health;

- Establishing a vision for Canadian involvement in global digestive health; and

- Optimizing the composition and regional distribution of the workforce to adapt to the changing landscape.

\section{Goal 2}

The CAG will focus on attracting new members while engaging, retaining and adding value for the existing membership of gastroenterologists, digestive health researchers and the digestive health constituency by:

- Developing and maintaining a data base of digestive health service providers;

- Ascertaining and addressing the needs of the digestive health services constituency; and

- Encouraging diversity of the CAG leadership.

\section{Goal 3}

The CAG will continue to develop and evaluate initiatives that improve access to, and the quality of, digestive health care delivery for all Canadians, by:

- Educating members about quality assessment, providing innovative tools, and developing, disseminating and monitoring the adoption of standards and guidelines;

- Improving access to quality care by engagement and education of the public and health policy makers through the CDHF and other means; and

- Identifying, recruiting and fostering the next generation of digestive health providers including practitioners, basic scientists, clinician scientists, educators, managers, advocates and leaders.

\section{Goal 4}

The CAG will enhance support for our research community's traditional strengths in biomedical and clinical research, while broadening its scope to the other Canadian Institutes of Health Research pillars, including quality assurance, by:

- Maintaining current and developing new funding partnerships to sustain and enhance research funding through studentships, fellowships, operating grants and career support awards;

- Supporting and promoting Clinician Researchers who are working in biomedical and clinical research by:

o Finding solutions with other organizations to remove barriers to pursuing a clinician scientist career;

- Training/attracting new people as clinician researchers; and

- Providing early and ongoing support to the clinician researcher.

- Promoting effective knowledge transfer so that research makes a difference in all aspects of digestive health, by:

- Encouraging clinicians and applied researchers to partner in shaping research priorities;
- Continuing to develop programs for clinicians to incorporate quality improvement research into their practices;

- Ensuring that research results are disseminated effectively to the membership and others; and

- Using the CDHF as a knowledge translation vehicle.

\section{Goal 5}

The CAG will prepare for the future needs and opportunities in digestive health care by establishing a future trends digestive health care Task Force whose mandate will include:

- Development of a health promotion and disease prevention strategy;

- Exploration of areas such as the role of diet and nutrition, microbiology, and oncology in digestive health care; and

- Exploration of new partnerships and opportunities such as the food industry.

\section{Goal 6}

The CAG will be the pre-eminent accredited provider for continuing education for our members and other digestive health providers, by:

- Identifying gaps in learner knowledge and skills, both perceived and unperceived, and anticipating emerging educational needs;

- Becoming a key provider of knowledge transfer through the effective and appropriate delivery of programs;

- Evaluating the impact of education;

- Facilitating the maintenance of certification program through a simple, integrated and streamlined system; and

- Advancing a regional outreach strategy linking with regional groups and provincial associations to support a range of activities.

\section{Principle}

The CAG will expand communication as a core competency that is supported by expertise, tailored to a diverse digestive health services constituency and delivered via multiple media, by:

- Developing a formal communication strategy that adheres to the following guiding principle: "All messages, whether core or customized, should be harmonious and aligned with the goals and aspirations of the CAG";

- Emphasizing face-to-face interactions and dialogue between CAG members and the digestive health community;

- Facilitating dialogue between researchers and clinicians;

- Facilitating dialogue between a diverse digestive health services constituency and the public through the CDHF; and

- Expanding the degree of dialogue with partners and other organizations to amplify the services we provide to members.

\section{DISCUSSION}

The current environment of constrained resources, increased competition and complexity brings with it the opportunity to reformulate health services, training, research and organizational systems that have become dated and nonresponsive. Transformational change required to correct the deficiencies of these systems will take extraordinary creativity. The situation has certainly forced the CAG to reassess its strategies and develop and align priorities.

Every organization is defined by a series of traits - the CAG has the ability, through the power of service and leadership, to effect change, transform situations and achieve greater good in the field of gastroenterology. There is an opportunity that meets a need, for the organization to play a role in this area nationally and internationally. To do this, the CAG and its foundation, the CDHF, will enhance existing relationships and develop new alliances supported by a culture of collaboration.

The CAG will continue to advance and enhance traditional areas of activity in advocacy, clinical, research and education domains. It is essential for the organization to remain current to fully support members in these areas. 
Enhanced advocacy to inform government and public agencies regarding the significant impact of digestive health and disease is required. Ongoing development of sophisticated and practical clinical guidelines and quality care initiatives for physicians in all jurisdictions will ensure continuing and enhanced delivery of high-quality gastrointestinal care across the country. Sustaining and promoting the creative delivery of highly developed education and training programs for all members is a vision shared throughout the organization. Technological advances must be used for enhanced delivery of clinical and educational programs and to evaluate their uptake and efficacy. Gastrointestinal health research moves the field forward and is about making people better. Over the past two decades, the CAG has been instrumental in partnering with industry, foundations and government agencies to build research excellence and capacity. The landscape of health sciences research across Canada is facing significant challenge, affecting strategies for health research at all levels. Collectively, with the CDHF and other stakeholders, the CAG must explore and support opportunities to integrate multidisciplinary research initiatives with clinical care. The success of the CDHF is critical to sustaining ongoing support of outstanding Canadian gastrointestinal scientists and trainees. Together, we must identify creative approaches to provide ongoing sustainable funding for Canadian digestive health and disease research. The CAG research agenda must be aligned with government and other funding agencies for successful prioritization and ongoing support to be achieved. A key to advancing the field is the ongoing need to develop, nurture and support a highly talented group of young trainees, physicians and scientists. The success of these people will ensure a relevant, vibrant and successful organization in the future to further advance the field. In addition, the CAG will continue to build on relationships that have been initiated with the global community to share knowledge and advance the discipline.

There have been significant technological innovations that have driven the discipline of gastroenterology during the past two decades. We must continue to critically assess and appraise future transformative innovations in areas such as nutrition, oncology, imaging and microbiology. It is imperative that we continue to evolve and grow as a discipline. The CAG must be involved in leading the development of evolving areas in gastroenterology so they are refined and tailored to best meet the needs of our patients.

\section{GOING FORWARD}

Significant gains have been achieved by the CAG during the past five years. The organization remains dedicated to professional education, research and patient care in all areas of digestive health and disease, in support of the economic and social health of all Canadians. The new CAG strategic plan is the result of the following: widespread consultation with members of the organization and related stakeholders; careful assessment of organizational strengths and weaknesses; and a sober assessment of the resources needed to get us there. It sets out six goals that will enable the CAG to achieve its full mandate, in all of its complexity to the membership; to show leadership within the wider health service, education and research community; and to demonstrate accountability and results to all constituents. The new strategic plan is ambitious and requires the commitment of all members to ensure the goals are achieved. It is time to acknowledge and embrace the goals and move forward to enhance the care of people we care for.

The CAG is committed to fulfilling its vision, mission and goals. The recently revised CAG organizational and governance structure provides a strong foundation that improves pathways and connections to support the goals of the strategic plan. Operationalization of the strategic plan is an important next step and requires the involvement of the entire membership. Since finalizing the strategic plan, the organization has taken specific initial steps to implement some programs, and progress is being made. Others will be implemented and addressed incrementally and iteratively in the months and years to come. Moving forward, member input will be sought to evaluate the ongoing work of the organization related to the strategic plan to ensure it meets the desired and expected outcomes.

The CAG is well positioned, as the national leader in gastroenterology, to meet the opportunities and challenges in the field in the years to come. Collectively with the CDHF, we have a strong voice to work with government, public agencies, industry and the public to ensure that the contributions of our members are recognized and play a significant role in the provision and reform of health service, educational and research areas.

We thank everyone who contributed to the development of the current strategic plan, and look forward to working with all CAG members in its successful realization. Implementation of the strategic plan is an iterative process with continuous review, evaluation and improvement of the plan itself. The CAG leadership welcomes your comments and suggestions to enhance the ongoing development and operation of the organization.

ACKNOWLEDGEMENTS: The CAG acknowledges Abbott Canada Inc for providing an unrestricted grant to support the strategic planning process; Sandra Daniels, Louise Hope and Palma Colacino for their ongoing professional support of the organization; Dr Jon Meddings for facilitating the strategic planning retreat; and the Syntegrity Group for facilitating the strategic planning process.

\section{REFERENCES}

1. Fedorak R, Sherman P. The 1993 Canadian Association of Gastroenterology Strategic Plan: Excellence in Achievement. Can J Gastroenterol 2003;17:683-4.

2. Sherman PM, Fedorak RN, Leddin D, Wallace JL. Canadian Association of Gastroenterology 2004 Strategic Plan. Can J Gastroenterol 2004;18:125-6.

3. Bridges R, Paterson W, Sinclair P, Morgan D. Summary of the Canadian Association of Gastroenterology 2004 Strategic Plan. Can J Gastroenterol 2010;24:164-7.

4. Beer S. In: Beyond Dispute: The Invention of Team Syntegrity. West Sussex: John Wiley \& Sons, 1994 


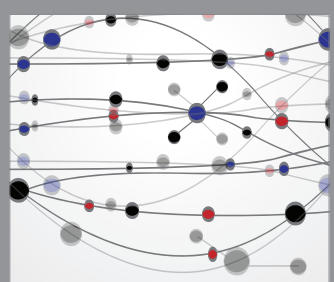

The Scientific World Journal
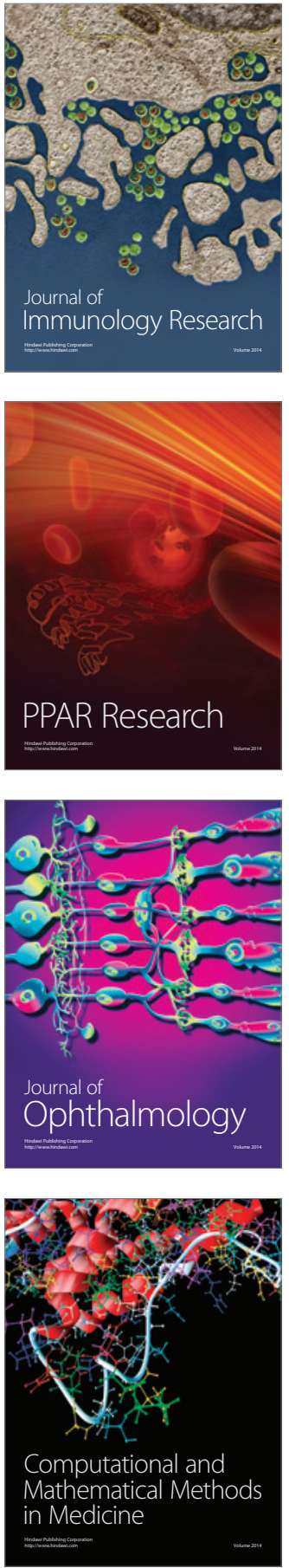

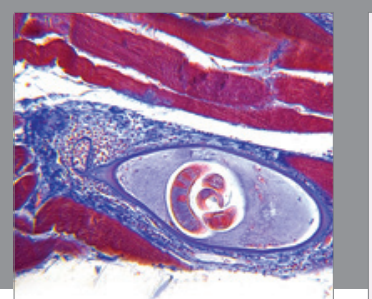

Gastroenterology Research and Practice

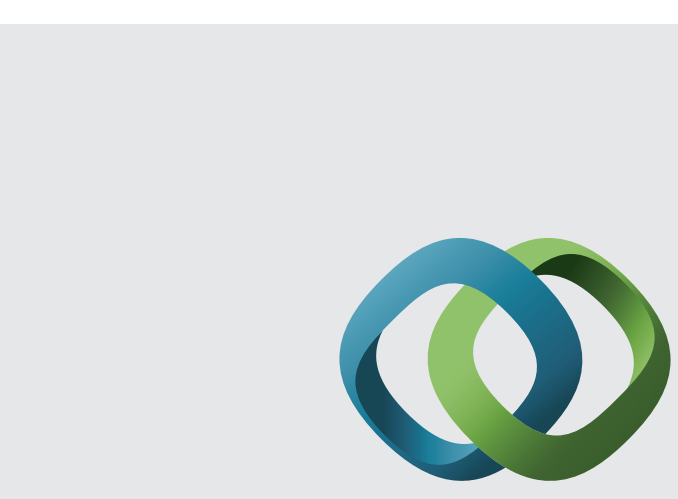

\section{Hindawi}

Submit your manuscripts at

http://www.hindawi.com
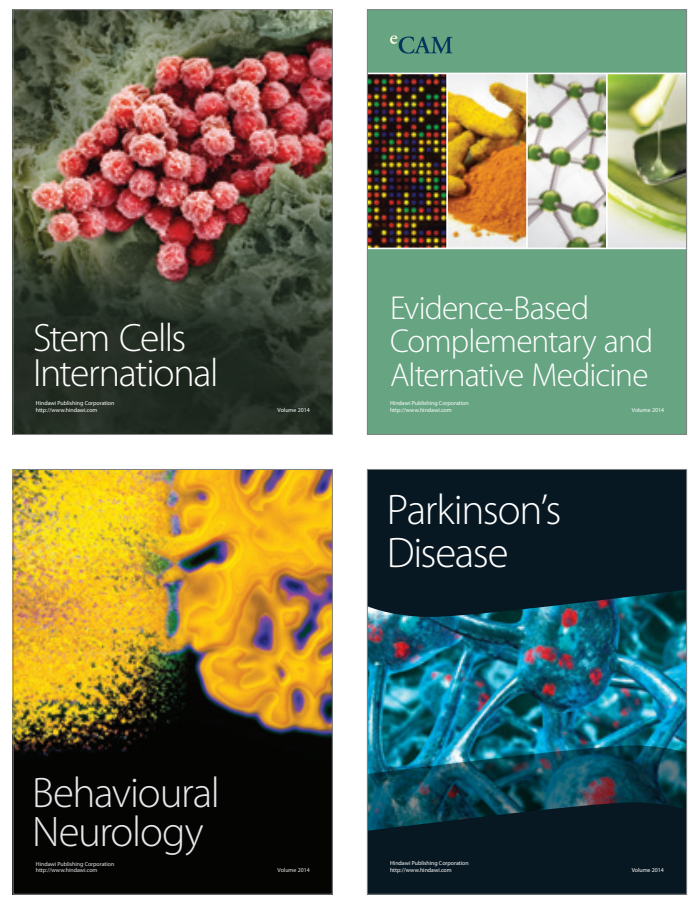
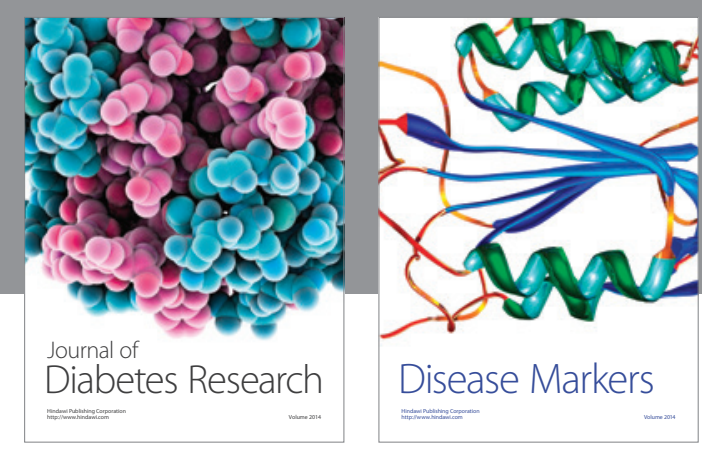

Disease Markers
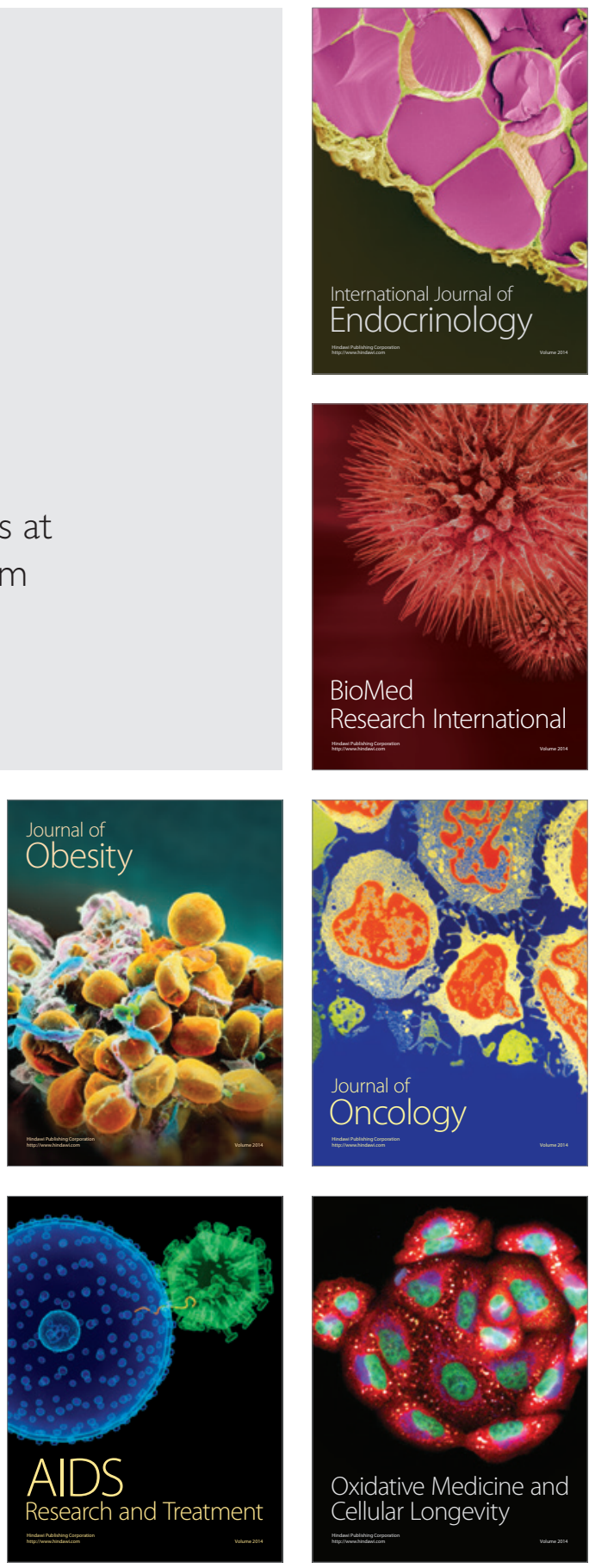